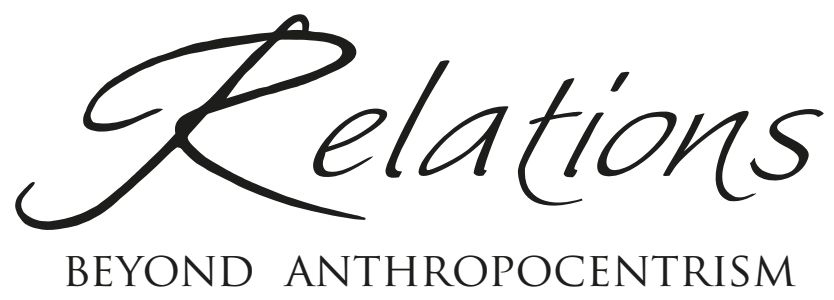

\author{
$9.1-2$ \\ NOVEMBER 2021 \\ Animals: Freedom, Justice, Welfare, \\ Moral Status, and Conflict Cases \\ Edited by Francesco Allegri
}

\author{
STUDIES \\ AND RESEARCH CONTRIBUTIONS
}

Pigs vs. Boars: The Ethics of Assisting Domesticated and Wild Animals

Beka Jalagania

The Chincoteague Ponies and What It Means To Be Free

Alexis Flower

Beyond the Fairy Tale of The Shape of Water: Reimagining the Creature

Viktorija Lankauskaite

Max Scheler e la possibilità di una nuova forma di antispecismo

Enrico R.A. Calogero Giannetto

Distributive Justice and Animal Welfare

Paola Morreale

Unitarianism or Hierarchical Approach for Moral Status?

A Very Subtle Difference

Francesco Allegri 


\section{Comments, Debates, Reports AND INTERVIEWS}

Animals and Justice: The Unfinished Journey

Paola Fossati

Author Guidelines 


\title{
Pigs vs. Boars \\ The Ethics of Assisting Domesticated and Wild Animals ${ }^{1}$
}

\section{Beka Jalagania}

Universität Mannheim

DOI: https://dx.doi.org/10.7358/rela-2021-0102-jala

beka.jalagania@gmail.com

\begin{abstract}
Among animal ethicists who accept that we have positive duties toward wild animals, there are some who maintain that these duties are considerably weaker than the duties we have toward domesticated animals, other things being equal. In this article I intend to examine whether this claim is true. To do this, I consider various factors that are often thought to render our duties to assist domesticated animals stronger than our duties to assist wild animals. My discussion will show that these factors fail to make our duties toward domesticated animals any stronger than our duties toward wild animals.
\end{abstract}

Keywords: animal ethics; domesticated animals; domestication; duties of assistance; laissez-faire intuition; partiality; special relationships; vulnerability and dependence; wild animals; wild animal suffering.

\section{INTRODUCTION}

In animal ethics, early discussions concerning duties to assist animals had primarily centered on domesticated animals ${ }^{2}$. In these discussions it was widely agreed that by engaging in animal domestication, a practice that creates vulnerable animals unable to survive on their own, humans acquired duties to care for the animals resulting from this practice. Some authors went so far as to argue that domestication renders human socie-

${ }^{1}$ I would like to thank Oscar Horta for his helpful comments on an earlier version of this article. humans.

${ }^{2}$ By "domesticated animal" I mean an animal who has been selectively bred by

Relations - 9.1-2 - November 2021

https://www.ledonline.it/Relations/ - Online ISSN 2280-9643 - Print ISSN 2283-3196 
ties as a whole collectively responsible for assisting domesticated animals (Donaldson and Kymlicka 2011, 94).

These early discussions largely excluded wild animals ${ }^{3}$. This exclusion was, partly, due to a misconception, commonly held by animal ethicists, about the quality of animal lives in the wild. This misconception is now referred to as the idyllic view of nature, according to which wild animals generally fare well, requiring no significant human assistance. Thanks to the diligent efforts of some authors ( $\mathrm{Ng} 1995$; Horta 2010a, 2010b; Tomasik 2015) to raise awareness of the harsh lives of wild animals and their systematic suffering, questions concerning wild animal assistance started to appear.

The question of whether we have duties to assist wild animals turned out to be rather contentious and divided animal ethicists into two camps. Drawing on Peter Singer's (1972) famous argument for the obligation to assist distant strangers, philosophers in one camp argued that we are required to assist suffering wild animals when we can do so without excessive cost to ourselves (Nussbaum 2006; Horta 2010b; McMahan 2015; Faria 2016). They maintained that if human suffering matters morally, there seems to be no reason why animal suffering should not matter too, unless we are speciesists and it is shown that speciesism is indefensible (Singer 1975; Pluhar 1995).

In contrast to this, philosophers in the other camp argued that unless we are in some way responsible for the suffering of wild animals, we are not required to assist them (Regan 1983; Pluhar 1995; Francione 2000; Gruen 2011). This view is now called the laissez-faire intuition (LFI), according to which we simply do not have general duties to assist wild animals (Palmer 2010; 2013). The LFI endorses an account of positive duties on which a requirement to assist others is created only on the basis of special relations or circumstances, one of which is being causally responsible for creating the need of assistance (Palmer 2010, 84). The troubling implication of this account, and the LFI in general, is that if we are not required to assist wild animals, and this is explained by the appeal to the lack of special relations with them, then we are also not required to assist complete strangers (humans) with whom we have no such relations. To recall Singer's famous drowning child analogy, the LFI and the account of positive duties that underlies this view would imply that we have no moral obligation to save the stranger child, even if we could do

${ }^{3}$ By "wild animal" I mean an animal who is undomesticated (i.e., has not been bred by humans) and lives independently in a natural environment that is generally undisturbed and unaffected by human actions (i.e., wilderness).

Relations - 9.1-2 - November 2021

https://www.ledonline.it/Relations/ - Online ISSN 2280-9643 - Print ISSN 2283-3196 
so at little or no cost to ourselves. As most of us would find this implication very hard to accept, the LFI should be given up.

But even if it is granted that we have duties to assist wild animals, there are some philosophers who argue that these duties are considerably weaker than our duties to assist domesticated animals, other things being equal (Nussbaum 2006; Palmer 2013). It is this claim that I want to critically examine here and see whether it is true. Considering the limited resources we have for assisting needy animals, exploring this claim will prove especially useful in conflict situations in which we are able to assist either domesticated or wild animals but not both.

\section{ANIMALS AND DUTIES OF ASSISTANCE}

As noted above, among animal ethicists who accept that we have positive duties toward wild animals, there are some who maintain that these duties are considerably weaker than the duties we have toward domesticated animals, other things being equal. For example, Martha Nussbaum argues that while we have duties to assist both domesticated and wild animals, our duties toward them are nevertheless different in strength. She states: "It seems plausible that we have less responsibility to protect gazelles than we do to protect domestic dogs and cats, since we are the guardians of the latter and they have evolved in symbiosis with us" (Nussbaum 2006, 379). On a similar note, Palmer points out that even if we accept that we are required to assist wild animals, this requirement will be much weaker compared to the requirement we have to assist domesticated animals. She writes: "There might be a different version of this view - that requirements to assist [wild animals] do exist in such cases but that they are much weaker where there's no prior entanglement" (Palmer 2013, 29).

Drawing on these claims, in the following subsections I will examine the question of whether our duties to assist domesticated animals are stronger than our duties to assist wild animals. To do this, I suggest that we look at the ways in which we come to be bound by duties to assist domesticated animals and see whether they provide stronger reasons to assist or care for these animals.

\subsection{Voluntary creation of domesticated animals}

While most domesticated animals are brought into existence by deliberate actions of humans, fully wild animals come into existence indepen- 
dently of any human involvement. Thus, while there is a human causal role in the existence of domesticated animals, there is no such role in the existence of fully wild animals. Could this mere fact, then, affect the strength of our positive duties toward domesticated and wild animals?

Suppose you are a pig farmer, raising and breeding pigs for commercial purposes. One day, at the request of your children, you decide to bring one of the piglets at home and raise him as a pet. Since, as a breeder, you are responsible for bringing the pig into existence, you acknowledge your obligation to take care of him by making sure that his basic needs are satisfied. Suppose also that your house is located next to a forest, where there is a solitary wild boar running around. You know that during winter her food becomes scarce and she starves most of the time. Unless you provide additional food for your pig who lives in your garden, he too will have to face starvation frequently. You are concerned about the well-being of your pig and the boar, but you realize that you can feed properly and thus prevent the starvation of only one of them. What are you required to do?

It could be claimed that, because you created the pig, you have the obligation to provide care for him and this would include making sure that he is well-fed. The defense of this claim could go as follows: by creating the pig you created a possibility that he can be harmed; that is, you put him in a situation in which it is possible that he can be harmed. Such a possibility did not exist before, nor was the pig in a situation in which he could have been harmed. The same cannot be said about the boar, because she came into existence independently of your actions. Now you have the obligation to make sure that the pig is not harmed and this obligation is stronger than your obligation to assist the boar, because you created the former but not the latter.

We can notice several problems with this argumentation. First, the fact that you created a needy being tells us that you acquired a duty to care for him, but this fact does not tell us anything about the strength of this duty - that is, while the creation of a needy being gives you a reason to assist him, it would be a mistake to think that it provides you with an additional reason to give such a being priority over the other equally needy being. Second, intuitively speaking, we do not ascribe moral relevance to the fact that by creating a being we also create a possibility that he can be harmed. If this fact was morally relevant, then it would have moral relevance not only when a created being is needy, but even after he is a self-sufficient adult, because the fact that we created a being persists as long as this being exists. Most parents believe that, after their children become self-sufficient adults, they are no longer required to care

Relations - 9.1-2 - November 2021

https://www.ledonline.it/Relations/ - Online ISSN 2280-9643 - Print ISSN 2283-3196 
for them, nor do they feel responsible for the harms their adult children may experience in the future. What thus seems to be the case is that the act of creation has no independent relevance. If we created a being who was self-sufficient from the very moment of his birth, we would not think that we bear any responsibility for the harms he may suffer throughout his life, even though we once created him and this way created a possibility that he could be harmed.

If being causally responsible for the existence of other beings as a property has any moral weight, then this property should have some moral weight in any other circumstances. If the presence of this property cannot make any difference in other circumstances, then it cannot be said to have any moral relevance. Suppose you have two children: one of them is your biological child, while another is an adopted one. If both of them become infected with a deadly virus and you can save only one of them, whom should you save? Would you think that your duty to assist your biological child is stronger than your duty to assist an adopted one, simply because you are causally responsible for the existence of the former and not of the latter? I believe most of us would answer these questions in the negative. Then, if your duties to care for both of your children are equal in strength, so should be our duties to care for domesticated and wild animals.

The relevance of this scenario can be challenged. It could be argued that in this scenario the only morally relevant difference between your children is not that you created one and not the other. It also matters that you adopted one and not the other. It could be argued, then, that this scenario does not necessarily show that your causal responsibility for the existence of your child has no moral weight. It may nevertheless have some moral weight; it is just that its moral weight might be counterbalanced by the moral weight that adoption carries and that is why we do not see the difference between the strength of the duties toward your biological and adopted children. But what moral weight does adoption carry? By adopting that child, it can be argued, you closed off his opportunities to be adopted, and thus taken care of, by others ${ }^{4}$ - that is, you deprived him of the opportunity to have different parents who would be happy to assist and save him in distress. This way, it could be claimed, adopting that child generates a requirement to assist him and that this requirement is as strong as your requirement to assist the child you created. Then, it could be that the moral weight of this requirement evens out the moral weight of the requirement generated by your causal

${ }^{4}$ For a similar point, see Burgess-Jackson 1998.

Relations - 9.1-2 - November 2021

https://www.ledonline.it/Relations/ - Online ISSN 2280-9643 - Print ISSN 2283-3196 
responsibility for the existence of your child and that is why the strength of your duties toward them are equal.

I think this objection can be easily avoided by adding an assumption to the scenario: that an adopted child is dying as a result of a genetic disease and that, if not you, nobody would ever adopt him. We can even add that the child would surely die if not adopted by you. I think that even in this modified scenario most of us would still think that your duties to assist both of your children have equal strength. If this is right, then the mere fact that we created domesticated animals cannot give us an additional reason to give priority to them over the equally needy wild animals.

\subsection{Causal responsibility for the vulnerability and dependence of domesticated animals}

If our causal role in the existence of domesticated animals could not provide a ground for asserting that our duties to assist them are stronger than our duties to assist wild animals, can our causal role in the vulnerability and dependence of domesticated animals provide such a ground? Palmer thinks that it can. She claims that humans are responsible for making domesticated animals vulnerable and dependent by selectively breeding them and, in some cases, they are made even more vulnerable and dependent once in existence by modifying their anatomical features (e.g., by clipping their coats, declawing, etc.) (Palmer 2013, 28).

Generally speaking, the practice of domestication is characterized by the change of animals' natural genetic traits into the traits that are profitable and desirable for humans. Such a change, in its turn, significantly diminishes the animals' natural skills necessary to be self-sufficient. Because of this, domesticated animals require regular human care and supervision to fare well. Considering how the practice of domestication works, Palmer's claim that through domestication humans make animals vulnerable and dependent may seem inappropriate. This is because an individual domesticated animal with a particular identity exists because of domestication and if that animal had not been domesticated, he would not have existed at all, and since domestication inherently causes vulnerability and dependence, domesticated animals cannot exist without being vulnerable and dependent. If being vulnerable and dependent is the only form or way of existence of domesticated animals, then it would be inappropriate to say that domestication makes animals vulnerable and dependent, for the word "makes" here suggests that there is a state

Relations - 9.1-2 - November 2021

https://www.ledonline.it/Relations/ - Online ISSN 2280-9643 - Print ISSN 2283-3196 
in which these animals are not vulnerable and dependent before being domesticated. But we have seen that in the case of domestication such a state does not exist, because without domestication these animals would not have existed at all. Thus, it would be more appropriate to say that domestication creates animals who are vulnerable and dependent and, in that sense, through domestication humans can only create such animals. If humans do not make domesticated animals vulnerable and dependent but only create them (or bring them into existence), then they will have causal responsibility only for the existence of domesticated animals and this brings us back to the previous discussion concerning the question of whether causal responsibility for the existence of domesticated animals gives us a stronger reason to assist them and I have shown that it does not.

While it makes no sense to say that through domestication humans make domesticated animals vulnerable and dependent, it does make sense to say that humans (can) make domesticated animals vulnerable and dependent after they are brought into existence. This is because the existing domesticated animals already have certain properties and/or abilities that can be altered in such ways as to make these animals less able and more susceptible to certain harms. Since making a being vulnerable and dependent does not directly affect his well-being negatively and since making him more susceptible to certain harms is not the same as harming him, it cannot be said that such an act is harmful and thus even pro tanto wrong. However, since making a being vulnerable and dependent significantly increases the likelihood that he can be harmed, such an act is at least morally problematic. But what does this tell us regarding our main question of whether making existing domesticated animals vulnerable and dependent gives us stronger reasons to assist them? Since answering this question very much relates to the later discussion concerning harming animals and our duties toward them, I will postpone further discussion of this question until later (section 2.4).

Perhaps Palmer can nevertheless insist that because the vulnerability and dependence of domesticated animals are human-caused or have a human origin, this alone can justify the claim that our duties to care for domesticated animals is stronger than our duties to care for wild animals. First of all, if domestication as a practice is neither harmful nor morally problematic and if through domestication humans do not make animals vulnerable and dependent, how can the mere fact that domestication has a human origin be of moral relevance? Moving on, to examine whether the human origin of vulnerability and dependence gives us stronger reasons to assist or care for domesticated animals, let us consider the fol-

Relations - 9.1-2 - November 2021

https://www.ledonline.it/Relations/ - Online ISSN 2280-9643 - Print ISSN 2283-3196 
lowing scenario: suppose you are a dog breeder - you breed dogs to sell them afterward. Similar to typical domesticated dogs, the dogs you breed are vulnerable and dependent and require regular care to fare well. At the request of your child, you decide to adopt one of them and bring him into your family. But the dog is not the only being who is adopted in your family. You also have an adopted child, who, like any other child, requires regular care and supervision. Now, on the assumption that your child and your dog have equal interests and that, if not you, nobody would ever adopt any of them, what would be the strength of your duties to care for them? If it is right that our reasons to assist others are stronger when their vulnerability and dependence is human-caused, then it follows that your duty to care for your dog is stronger than your duty to care for your child, because the vulnerability and dependence in the case of your dog are human-caused, while in the case of your child they are natural. But I do not think that many would accept this implication. Most of us would hold that, as long as your child and your dog have equal interests, your duties to care for them would be equal, and if this is right, then our duties toward domesticated and wild animals would be equal too.

\subsection{Special relationships with domesticated animals}

Although most of us do not have special relationships with most domesticated animals, some of us certainly are related to some domesticated animals in a special way. A paradigmatic example of such special relation is pet adoption. For most people adopting a pet means bringing a new member into their families, where an animal will be loved and adequately cared for. Most people are not related to wild animals in that way. Although some humans may develop close relationships with some wild animals and may even coexist with them to some extent, special relationships between ordinary people and fully wild animals are almost non-existent. This difference, then, could provide some justification for the claim that our reasons or duties to assist at least some domesticated animals are stronger than our reasons or duties to assist wild animals. In what follows I will examine two possible ways of developing such a justification: the first concerns an act of adoption, while the second focuses on the value of special relationships.

It could be argued that by adopting an animal one closes off his opportunities to be adopted by others who would not only care for him but also prioritize his well-being in conflict situations. Thus, in conflict cases, an adopter should do what a different or even better adopter could

Relations - 9.1-2 - November 2021

https://www.ledonline.it/Relations/ - Online ISSN 2280-9643 - Print ISSN 2283-3196 
have done - prioritize the well-being of an adopted animal. For that reason, it could be said, adopting an animal gives us a stronger reason to assist an adopted animal rather than a stranger wild animal ${ }^{5}$.

This argument is problematic in various ways. First of all, it should be noted that while adoption implies that an adopter undertakes a duty to care for an adopted animal, it by no means implies the requirement that in conflict cases this animal should be favored or given priority over the equally needy animal. This means that in conflict cases favoring or prioritizing an adopted animal requires justification. Second, the premise that one should treat an adopted animal similar to the way a better adopter would treat that animal is question-begging, for it assumes that a better adopter is already justified in prioritizing the well-being of an adopted animal. It might be that a better adopter could have really prioritized that animal, but he too would be required to justify doing that. The truth is that in conflict cases any adopter, including a better one, would need a justification for favoring an adopted animal.

The claim that we owe more to domesticated animals than we do to wild animals can be defended by the appeal to special relationships that may develop between humans and domesticated animals. Such relationships are characteristic of humans and animals living together as one family. Indeed, humans and their animal companions often develop deep emotional bonds and powerful loving relationships that are mutual and can be very intense. Considering their value and significance to some humans, such relationships are often thought to provide some justification for giving priority to the interest of individuals to whom we are specially related. Whether special relationships really provide such justification is a subject of a heated debate between the proponents of partiality and impartiality (see, for example, Jollimore 2018).

The case for impartiality seems rather simple: since all morally considerable beings matter equally, they should be treated as equals. If their needs are equal, special considerations aside, then moral reasons to satisfy their needs are also equal. To say that despite their equal needs our moral reasons to satisfy their needs are not equal requires justification. For example, if my cat and a feral cat are dying but I can save only one of them, then, on the assumption that they will equally benefit from being

${ }^{5}$ It is worth noting that when it comes to adoption, any kind of animal - wild or domesticated - can be adopted, however, as it typically is the case, adopted companion animals are domesticated ones and the conflict case here refers to conflicting interests of domesticated animals living in human families and fully wild animals living in the wild. 
saved, my moral reasons to save each of them are equal. Saying that my moral reasons are not equal calls for justification. Thus, the proponents of partiality will need to appeal to the allegedly morally relevant differences between my cat and a feral cat to provide such a justification. They could argue that my reason to save my cat is stronger than the reason to save a feral cat because I have a special relationship with my cat that I do not have with a feral cat. After all, my cat is not just another animal; he is an animal with whom I developed a deep and meaningful relationship that provides a moral reason for treating him in a special way - to prioritize his well-being over the well-being of an equally needy but a stranger animal.

Simon Keller, in his book Partiality, provides a comprehensive assessment of the different defenses of partiality. In a lengthy discussion, he critically examines and rejects the relationships view, according to which our reasons to be partial are grounded in the intrinsic value of our special relationships, before he develops his own - the individuals view, according to which our reasons to be partial are grounded in the value of individuals with whom we share our special relationships. Keller's main criticism toward the relationships view is that, in explaining why we have reasons to be partial, this view relies on the intrinsic value of special relationships, without making a reference to the significance these relationships have for us, for our well-being. As he notes, this view "attempts to explain the importance of human relationships by dissociating them from the contributions they make to human needs and interests. It drags human relationships from their human context" (Keller 2013, 77). Since Keller effectively and persuasively discredits the plausibility of the relationships view, I will not be concerned with examining it further and directly move on to the evaluation of his own view ${ }^{6}$.

Unlike the relationships view, Keller's individuals view states that our motives for being partial toward certain individuals are best explained by the reference to the value of these individuals. Indeed, when we rush to assist the individuals with whom we share special relationships, the motivating factor of our actions seems to be the individuals themselves and not the relationships we have with them. In assisting them we do not think about the value of our special relationships; rather, we think about the value of these individuals. Although the individuals view best explains our actions when we are partial toward certain individuals, if it is to gain any credibility, it further needs to explain why we should be

${ }^{6}$ For a thorough and powerful criticism of the relationships view defended by Joseph Raz, Samuel Scheffler, Niko Kolodny, and others, see Keller 2013, 45-77.

Relations - 9.1-2 - November 2021

https://www.ledonline.it/Relations/ - Online ISSN 2280-9643 - Print ISSN 2283-3196 
partial. In other words, the individuals view owes us a justification for the claim that our duties to assist individuals with whom we have special relationships are stronger than our duties to assist complete strangers, other things being equal. Keller acknowledges the need for such a justification:

Behind the puzzle of partiality, and behind the main problem for the individuals view, is the assumption that if two entities have the same kinds of value, then any reasons generated by the value of the first entity must also be generated by the value of the second entity. If the individuals view is to succeed, then it must challenge that assumption. It must find a way to say that you can have a reason to give certain treatment to one person, because he has a certain value, without having the same reason to give the same treatment to another person, even though she has the same value. (Keller 2013, 114)

But can Keller's view solve the puzzle of partiality? Can this view explain why we should treat equally valuable and equally needy beings unequally? This is what Keller has to say in response:

The individuals view has the option of saying that it is a primitive fact, admitting of no further explanation, that the value of an individual generates certain reasons, duties, and permissions for some agents, without generating the same reasons, duties, and permissions for other agents. The main objection to the individuals view is that it seems unable to explain why we have special reasons regarding the particular individuals with whom we share special relationships; it is an option for the individuals view to respond by saying, "We just do". The puzzle of partiality is the puzzle of saying why we should treat some people differently from others, even when those others are no less inherently valuable; it is an option for the individuals view to respond by saying, "We just should". (ibid., 138)

This response is as inadequate as it is disappointing. An adequate account of partiality must be able to explain why we should be partial toward certain individuals if it is to outweigh the demands of impartiality, and Keller's resort to the primitivism about the reasons of partiality seems rather an ad hoc move and insufficient. It is also disappointing because, after all, Keller's "explanation" for our having special moral reasons of partiality is that there is no explanation. Such an uninformative response will not be able to convince even a hesitating impartialist, let alone change the minds of avid proponents of impartiality. Thus, I conclude that the individuals view is deeply unsatisfactory and unpersuasive, and that special relationships cannot make our moral reasons to assist animals with whom we have special relationships any stronger than the moral reasons we have for assisting animals with whom we lack such relationships.

Relations - 9.1-2 - November 2021

https://www.ledonline.it/Relations/ - Online ISSN 2280-9643 - Print ISSN 2283-3196 


\subsection{Prior harmful actions}

Harmful actions of humans often cause victims to be in need of assistance and thus generate the duties to assist them. Although domesticated animals are the typical victims of human harms, they are not the only ones; wild animals too suffer harms from the actions of humans. Thus, my discussion of the duties to assist the victims of human harms will concern not only domesticated animals but also wild ones. In that sense, this subsection will not resolve the specific question of whether our reasons to assist domesticated animals are stronger than our reasons to assist wild ones. Rather, the question I am concerned with here is whether our duties of assistance that are generated as a result of our prior harmful actions are any stronger than our duties of assistance that have a different origin, other things being equal. Exploring this question will prove useful, for it will provide guidance for conflict cases in which among the animals we are required to assist some are the animals to whom we owe assistance because we harmed them, while some others are the animals toward whom we have duties of assistance on other grounds.

Let us start exploring the question by considering the following scenario: suppose that the chemical waste released from your factory located nearby a forest has deteriorated the soil that used to provide food for a group of wild animals (Group A). Due to the resulting food shortage, these animals are having a hard time finding enough food to feed themselves and most of the time they are starving. On the other side of the forest, due to a natural forest fire, another group of wild animals (Group B) has lost a big part of their food supply and they too are starving most of the time. On the assumption that you can relieve or end the suffering of only one of these groups of animals and all other things are equal, which one should you assist?

It is clear that you have the obligation to assist both groups of animals, although your obligations to assist each of them differ in their origins. Your duty to assist animals in Group A is special which you acquired through your harmful actions. You made these animals worse off and now you have a special duty to restore the injustice - that is, you ought to compensate for the loss they suffered as a result of your actions and restore their condition at least to the point it was prior to the infliction of harm. Your duty to assist animals in Group B is general which is imposed on you simply because it is within your power to end their suffering and you can do so without excessive cost to yourself. As it seems, your duty to assist animals in Group A is grounded in the requirement of justice, while your duty to assist animals in Group B is derived from the

Relations - 9.1-2 - November 2021

https://www.ledonline.it/Relations/ - Online ISSN 2280-9643 - Print ISSN 2283-3196 
general requirement of morality. Having clarified the difference between the grounds of your duties to assist both groups of animals, we can ask again: which group are you required to assist?

In conflict cases like this, a standard view is that, all other things being equal, the requirements of justice take priority. This view employs an assumption that negative duties are much more stringent than positive duties (Palmer 2010, 88). If that is so, then the requirements that are created as a result of the violation of negative duties will be stricter than the general requirements of morality. Such requirements are the requirements of justice, that demand that the individuals who are the victims of injustice should be given what they were deprived of or what they would have had had they not been treated unfairly ${ }^{7}$. In relation to the animals in Group A, you violated your negative duty not to harm them by damaging their food supply and making them starve. That is why your obligation to assist them now is grounded in the requirements of justice. What would, then, a standard view require you to do? For simplicity, let us put aside difficulties associated with collective responsibility and assume that you are directly causally responsible for the starvation of the animals in Group A. On the standard view, then, you ought to give priority to their well-being and use all your limited recourses to mitigate or end their suffering. This is because the animals in Group A are the victims of injustice, since you unjustifiably made them worse off by deteriorating the soil on which their livelihood depends. Consequentialists would deny this. They would insist that, since both actions - alleviating or ending the suffering of animals in Group A or Group B - would produce the same amount of value, either of them is optional and none of them has a priority over the other.

I find the standard view intuitively very plausible. Unfortunately, due to the scope and focus of this article, I cannot offer a full defense of this view, but below I can mention a few considerations that will demonstrate its intuitive plausibility.

So, why are negative duties stronger than positive duties? I suggest that the plausibility of this claim rests on the assumption that doing harm is worse than allowing harm. Since the violation of negative duties constitutes doing harm and the violation of positive duties constitutes allowing

${ }^{7}$ It should be noted here that the requirements of justice are applicable only to the agents who are the perpetrators of injustices and it is the perpetrators' standpoint from which the requirements of justice have more force. Otherwise, if you are in a position to assist two individuals, one of whom is the victim of injustice, but you are not causally responsible for this injustice, I do not see why the fact that one suffered injustice and another did not should have a moral significance for you. 
harm, it follows that the violation of negative duties is worse than the violation of positive duties. The latter claim explains why negative duties are stronger than positive duties: if a particular action is worse than the other, it is natural that the requirement that prohibits the worse action will be stronger than the other. For example, if killing is worse than letting die, then an act of killing will be more strongly prohibited than an act of letting die. As a matter of fact, saying that negative duties are stronger than positive duties is just another way to say that the violation of negative duties is worse than the violation of positive duties. If negative duties are stronger than positive duties, then the requirements of justice that are generated by the violation of negative duties will be stronger as well. But in order for this argumentation to gain any credibility, the fundamental assumption that doing harm is worse than allowing harm must be properly defended.

Frances Kamm offers a valuable insight into why doing harm is worse than allowing harm, by demonstrating why killing, which is an instance of doing harm, is worse than letting die, which is an instance of allowing harm. First, she notes that to see that killing is worse than letting die, we need to ask whether we would think it permissible to impose the same losses on the individuals who committed the acts of killing and letting die, assuming that the imposition of these losses was necessary to bring the victims back to life. She argues that, while most of us would accept the killing of a killer, most of us would think it impermissible to kill the individual who let someone die. She also uncovers the essential features that draw the difference between killing and letting die and also, arguably, commit us intuitively to the idea that the former is worse than the latter: (a) in killing, we introduce a threat that was not previously present, while in letting die, a (potential) threat is already present; (b) in letting die, it is always the case that a victim loses a life that he would have had only with our assistance at that time; (c) in killing, we initiate an interference with the victim, while in letting die, we avoid being interfered with (Kamm 2007, 17-19).

Another defense of the claim that killing is worse than letting die is this: if killing and letting die are morally equivalent, then, other things being equal, the use of such harmful means that is justified in preventing one, will be justified in preventing the other ${ }^{8}$. Let us consider the following scenarios. Suppose that in Case 1 an aggressor unjustly attacks you with the intention to kill you. Since you can defend your life only by killing the aggressor, you shoot him dead. Now, suppose in Case 2 you fell in a swamp and are slowly drowning. Luckily, you notice that there is a stranger walking nearby and ask him for help. However, upon

${ }^{8}$ For a similar point, see Frowe 2007, 60-61.

Relations - 9.1-2 - November 2021

https://www.ledonline.it/Relations/ - Online ISSN 2280-9643 - Print ISSN 2283-3196 
approaching, he tells you that he would rather watch you die than save you and refuses to offer any assistance. In desperation, you realize that if you shoot him dead with your gun, his body will fall into the swamp, then you can crawl up the fallen body and get out of the swamp. Since there are no other alternative ways to save your life, you kill the stranger.

The situation in Case 1 is a clear case of a justified self-defense. It is more than obvious that you are justified in using deadly force against the attacker who was going to kill you. But are you justified in using deadly force against the stranger in Case 2? I highly doubt that you are. Most of us would consider the killing of the stranger grossly impermissible. Yet if killing and letting die were morally equivalent, the use of deadly force in both cases would be justified, other things being equal. But it seems that you are not justified in killing the stranger in Case 2. Thus, killing and letting die are not morally equivalent. The fact that the use of deadly force is justified only in Case 1 shows that killing is worse than letting die.

If we find the discussion above intuitively appealing, then this would provide support for the claim that, other things being equal, the requirements of justice are stricter than the general requirements of morality, as the standard view states, and thus you ought to prioritize the well-being of the animals who are the victims of injustice for which you are causally responsible.

Finally, I will now turn to the discussion I started in section 2.2 and postponed until this moment. The discussion concerns the question of whether making existing domesticated animals vulnerable and dependent gives us stronger reasons to assist them. The reason why I postponed discussing this question until this moment is that this question is morally analogous to the recently discussed question of whether the fact that one's need for assistance is caused by the harmful actions of ours gives us stronger reasons to assist harmed individuals. Previously I noted that although making animals vulnerable and dependent is not a harm, it is nevertheless morally problematic. This is because making animals less able and less self-sufficient significantly increases the likelihood that they can be harmed. But since making animals more susceptible to certain harms is not the same as actually harming them, the duties that are created by making animals more vulnerable will not be any stronger than the duties that are created by bringing vulnerable animals into existence. Thus, as long as making animals more susceptible to certain harms does not result in actually harming them, the requirements of justice are not generated. But as soon as they experience harm as a result of being made more susceptible by our actions, the requirements of justice thus created will demand that we give priority to their needs, as I have argued above.

Relations - 9.1-2 - November 2021

https://www.ledonline.it/Relations/ - Online ISSN 2280-9643 - Print ISSN 2283-3196 


\section{CONCLUSION}

The question of whether we have duties to assist wild animals at all is a matter of dispute among animal ethicists. But even if some philosophers accept that we do have duties to assist wild animals, they nevertheless maintain that these duties are considerably weaker than the duties to assist domesticated animals. In this article I critically examined this claim. In doing so I explored various possible grounds that could substantiate this claim. My examination of these grounds showed that they fail to render our duties to assist domesticated animals any stronger than our duties to assist wild animals.

\section{REFERENCES}

Burgess-Jackson, Keith. 1998. "Doing Right by Our Animal Companions". Journal of Ethics 2: 159-185.

Donaldson, Sue, and Will Kymlicka. 2011. Zoopolis: A Political Theory of Animal Rights. New York: Oxford University Press.

Faria, Catia. 2016. Animal Ethics Goes Wild: The Problem of Wild Animal Suffering and Intervention in Nature. PhD Thesis, Pompeu Fabra University.

Francione, Gary. 2000. Introduction to Animal Rights: Your Child or the Dog? Philadelphia: Temple University Press.

Frowe, Helen. 2007. "Killing John to Save Mary: A Defense of the Moral Distinction Between Killing and Letting Die". In Action, Etbics, and Responsibility, edited by Joseph K. Campbell et al., 47-66. Cambridge (MA): MIT Press.

Gruen, Lori. 2011. Ethics and Animals. Cambridge: Cambridge University Press.

Horta, Oscar. 2010a. "Debunking the Idyllic View of Natural Processes: Population Dynamics and Suffering in the Wild". Télos 17: 73-90.

Horta, Oscar. 2010b. "The Ethics of the Ecology of Fear against the Nonspeciesist Paradigm: A Shift in the Aims of Intervention in Nature". Between the Species 13 (10): 163-187.

Jollimore, Troy. 2018. "Impartiality". In The Stanford Encyclopedia of Philosophy. https://plato.stanford.edu/archives/win2018/entries/impartiality/

Kamm, Frances. 2007. Intricate Ethics: Rights, Responsibilities, and Permissible Harm. New York: Oxford University Press.

Keller, Simon. 2013. Partiality. Princeton: Princeton University Press.

McMahan, Jeff. 2015. "The Moral Problem of Predation". In Philosophy Comes to Dinner: Arguments about the Ethics of Eating, edited by Andrew Chignell et al., 268-294. New York: Routledge.

Ng, Yewk. 1995. "Towards Welfare Biology: Evolutionary Economics of Animal Consciousness and Suffering". Biology and Philosophy 10 (1): 255-285. 
Nussbaum, Martha. 2006. Frontiers of Justice: Disability, Nationality, Species Membership. Cambridge (MA): Harvard University Press.

Palmer, Clare. 2010. Animal Ethics in Context. New York: Columbia University Press.

Palmer, Clare. 2013. "What (If Anything) Do We Owe to Wild Animals?”. Between the Species 16 (1): 15-38.

Pluhar, Evelyn. 1995. Beyond Prejudice: The Moral Significance of Human and Nonbuman Animals. Durham - London: Duke University Press.

Regan, Tom. 1983. The Case for Animal Rights. Berkeley: University of California Press.

Singer, Peter. 1972. "Famine, Affluence, and Morality". Philosophy \& Public Affairs 1 (3): 229-243.

Singer, Peter. 1975. Animal Liberation. New York: New York Review.

Tomasik, Brian. 2015. “The Importance of Wild Animal Suffering”. Relations. Beyond Anthropocentrism 3 (2): 133-152. 